\title{
Sea level variability in the Strait of Gibraltar from along-track high spatial resolution altimeter products
}

Jesús Gómez-Enri (1), Stefano Vignudelli (2), Alfredo Izquierdo (1), Marcello Passaro (3), Carlos José González (1), Paolo Cipollini (4), Miguel Bruno (1), Óscar Álvarez (1), Rafael Mañanes (1)

(1)

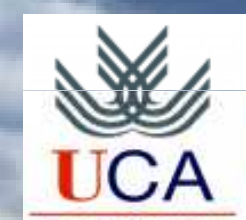

Universidad

Universidaa
de Cádiz
(2)

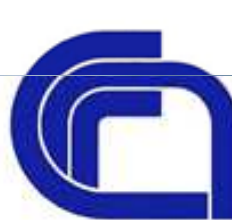

(3)

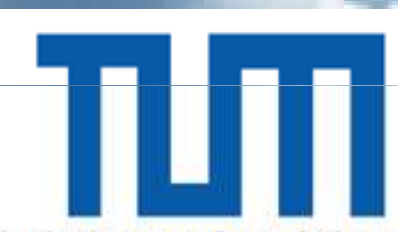

Technischen Universität München

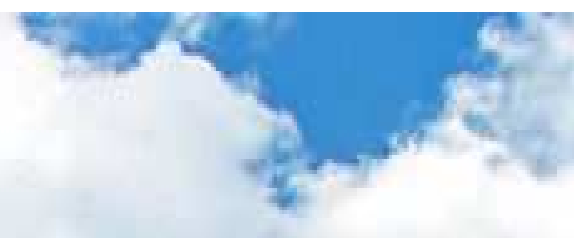

Consiglio

Nazionale delle

Ricerche

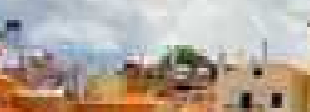

$1 \cdot 1 a \cdot b^{3}$ th

1. , MU1, II

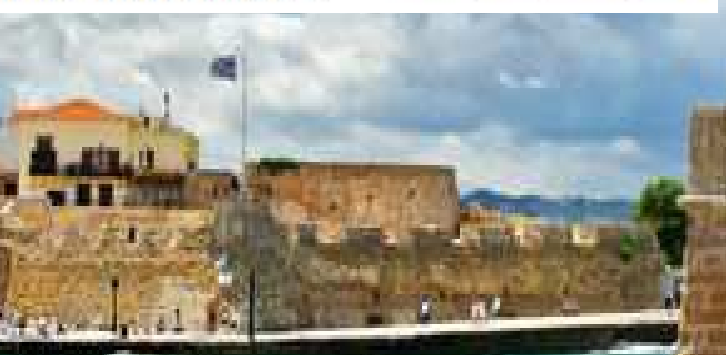

(4)

Cesa

European Space Agency

International Review Workshop on Satellite Altimetry CAL/VAL Activities and Applications (Chania - Crete - Greece, 23-26 April 2018) 

along-track high spatial resolution altimeter products

\section{OUTLINE}

\section{OBJECTIVE}

\section{STUDY AREA}

\section{DATA SETS AND METHODS}

\section{RESULTS}

\section{CONCLUSIONS}

\section{ACKNOWLEDGMENTS}



along-track high spatial resolution altimeter products

Acknowledgments

Conclusions

Results

Data sets and Methods

Study Area

Objective

International Review Workshop on Satellite Altimetry CAL/VAL Activities and Applications (Chania - Crete - Greece, 23-26 April 2018) 


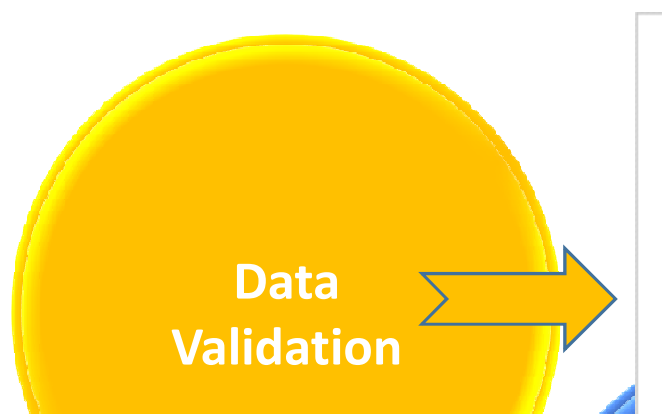

\section{Coastal Altimetry Products in the Strait of Gibraltar}

Jesús Gómez-Enri, Paolo Cipollini, Senior Member, IEEE, Marcello Passaro, Stefano Vignudelli, Begoña Tejedor, and Josep Coca

Abstract-This paper analyzes the availability and accuracy of coastal altimetry sea level products in the Strait of Gibraltar. All possible repens of in the eastern and western portion of the strin. For Envisat, along-track sea level anomalies (SLAs) at 18- Hz post. ing rate were computed using ranges from two sources, namely, the official Sensor Geophysical Data Records (SGDRs) and the outputs of a coastal waveform retracker, the Adaptive Leading Edge Subwaveform (ALES) retracker; in addition, SLAs at $1 \mathrm{~Hz}$ were obtained from the Centre for Topographic studies of the 40 Hz was also computed both frim SGDR a d A IS rang SLA The sea state bins correction was reconputed for the ALES retracked Envisat SLA. The quality of these altimeter products was validated using two tide gauges located on the southern coast of Spain. For Envisat, the availability of data close to the coast depends crucially on the strategy followed for data screening. Most of the rejected data were due to the radar instrument operating in a low-precision the accuracy of the Envint SIAs from ALSS compared to the standard (SGDR) and the reprocessed CTOH data sets. AltiKa shows higher accuracy, with no significant differences between SGDR and ALES. The use of products from both missions allows longer times series, leading to a better understanding of the hydrodynamic processes in the study area.

Index Terms-Coastal altimetry, data screening, retracking, Strait of Gibraltar (SoG), tide gauge, validation.

I. INTRODUCTION the oceanographic processes in the Strait of Gibraltar

Cof
A global analysis of the sea level variability near the coasts using satellite altimeter data is now a realistic prospect by virtue of the availability of new reprocessed data with higher alongtrack spatial resolutions and better accuracy. However, putting his into effect requires a consistent validation effort.

Reprocessing efforts are targeting the two main factors that compromise the availability and quality of altimeter data near the coasts with respect to open ocean: 1) inaccuracies in the retrieval of geophysical information from the shape of the mean returned waveforms from the reflected surface (this retrieval is normally done by some waveform fitting procedures known as retracking) and 2) a poorer characterization of some of the seophysical corrections applied to the data. Present allimetry missio (Cryosat-2 AltiKa and Jason-2) and near foture

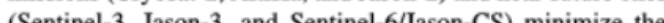
impact of these factors on deta quality by virtse of ste art radiomeric ase of he SARSAR- node operation (Cryosat-2 and all fature missions). For past missions (ERS-1/2, Topex/Poseidon, Envisat, GFO, and Jason-1), more efforts still need to be made in order to include their products in coastal applications and models [2]

A radar altimeter measures the two-way travel time of the emitted/reflected signal/echo and the returned power. The amount of energy received is recorded onboard in a time series

COASTAL altimetry has become a mature discipline owing called a "waveform." The pulse repetition frequency (PRF) Nitha regime

\section{Objective}

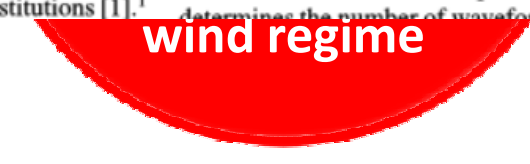

International Review Workshop on Satellite Altimetry CAL/VAL Activities and Applications (Chania - Crete - Greece, 23-26 April 2018) 


\section{Acknowledgments}

Conclusions

Results

Data sets and Methods

Study Area

Objective
Overall, the results for the reprocessed ALES Envisat are improved compared to the standard (SGDR) and the reprocessed $\mathrm{CTOH}$ data sets. The mean along-track rmse in the Strait between ALES and the tide gauge is below 14/12 cm (D\#0360/A\#0831), which represents about a $20 \%$ improvement with respect to the SGDR.

were obtained from the Centre for Topographic studies of the Ocean and avilability and quality of altimeter data near the coasts with respect to open ocean: 1) inaccuracies in the retrieval of geophysical information from the shape of the mean returned waveforms from the reflected surface (this retrieval

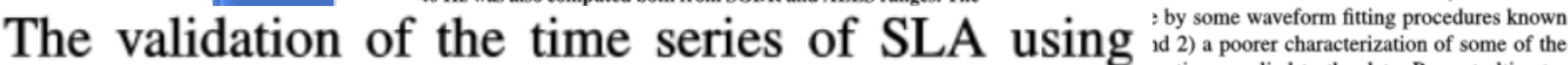

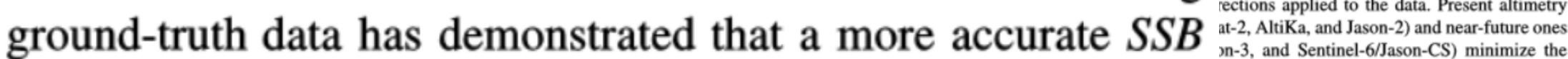
correction improves the comparison against in situ data.

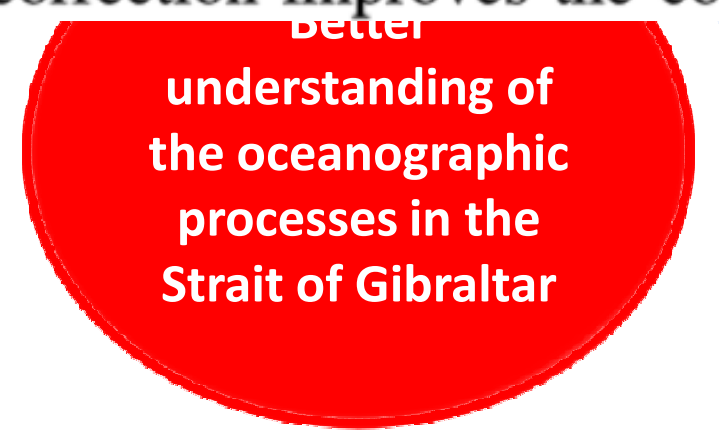

shows higher accuracy, with no significant differences between SGDR and ALES. The use of products from both missions allows longer times series, leading to a better understanding of the hydro-

dynamic processes in the study area.

Index Terms-Coastal altimetry, data screening, retracking, Strait of Gibraltar (SoG), tide gauge, validation.

I. INTRODUCTION

Strait of Gibraltar EE, Marcello Passaro,

is of the sea level variability near the coasts imeter data is now a realistic prospect by virtuc y of new reprocessed data with higher alongslutions and better accuracy. However, putting quires a consistent validation effor. n-3, and Sentinel-6/Jason-CS) minimize the actors on data quality by virtue of state-of-theserformance (Cryosat-2, AltiKa, and Jason-2), A AR-mode operation (Cryosat-2 and all future missions). For past missions (ERS-1/2, Topex/Poseidon, Envisat, GFO, and Jason-1), more efforts still need to be made in order to include their products in coastal applications and models [2].

A radar altimeter measures the two-way travel time of the emitted/reflected signal/echo and the returned power. The

COASTAL altimetry has become a mature discipline owing amount of energy received is recorded onboard in a time series

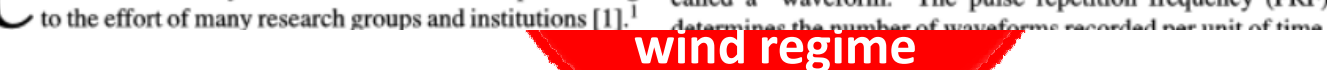




\section{Sea level variability in the Strait of Gibraltar from} along-track high spatial resolution altimeter products

The Effects of Nonrectangular Cross Section, Friction, and Barotropic Fluctuations on the Exchange through the Strait of Gibraltar

MYRIAM BORMANS AND CHRIS GARRETT

Department of Oceanography, Dalhor (Manuscript received 3 Augt

GEOPHYSICAL RESEARCH LETTERS, VOL. 27, NO. 18, PAGES 2949-2952, SEPTEMBER 15, 2000

Western Mediterranean sea-level rise: changing exchange flow through the Strait of Gibraltar

Tetjana Ross and Chris Garrett

Department of Physics and Astronormy, University of Victoria, B.C., Canada.

Pierre-Yves Le Traon

Oceanography Department, CLS Space C GEOPHYSICAL RESEARCH LETTERS, VOL. 32, L04604, doi:10.1029/2004GL021760, 2005

Acknowledgments

Conclusions

Results

Data sets and

Methods

Study Area
Wind driven upwelling along the African coast of the Strait of Gibraltar

S. Stanichny, ${ }^{1}$ V. Tigny, ${ }^{2}$ R. Stanichnaya, ${ }^{1}$ and S. Djenidi ${ }^{2}$

Received 14 October 2004; revised 17 January 2005; accepted 21 January 2005; published 18 February 2005.

\section{Objective}

International Review Workshop on Satellite Altimetry CAL/VAL Activities and Applications (Chania - Crete - Greece, 23-26 April 2018) 

along-track high spatial resolution altimeter products

The Effects of Nonrectangular Cross Section, Friction, and Barotropic Fluctuations on the Exchange through the Strait of Gibraltar

\section{Acknowledgments}

Conclusions

Results

Data sets and

Methods

Study Area

\section{Objective}

Wind driven upwelling along the African coast of the Strait of Gibraltar

S. Stanichny, ${ }^{1}$ V. Tigny, ${ }^{2}$ R. Stanichnaya, ${ }^{1}$ and S. Djenidi ${ }^{2}$

Received 14 October 2004; revised 17 January 2005; accepted 21 January 2005; published 18 February 2005 
Sea level variability in the Strait of Gibraltar from along-track high spatial resolution altimeter products

The Strait of Gibraltar: where two worlds meet...

\section{Acknowledgments}

Conclusions

Results

Data sets and

Methods

Study Area

Objective
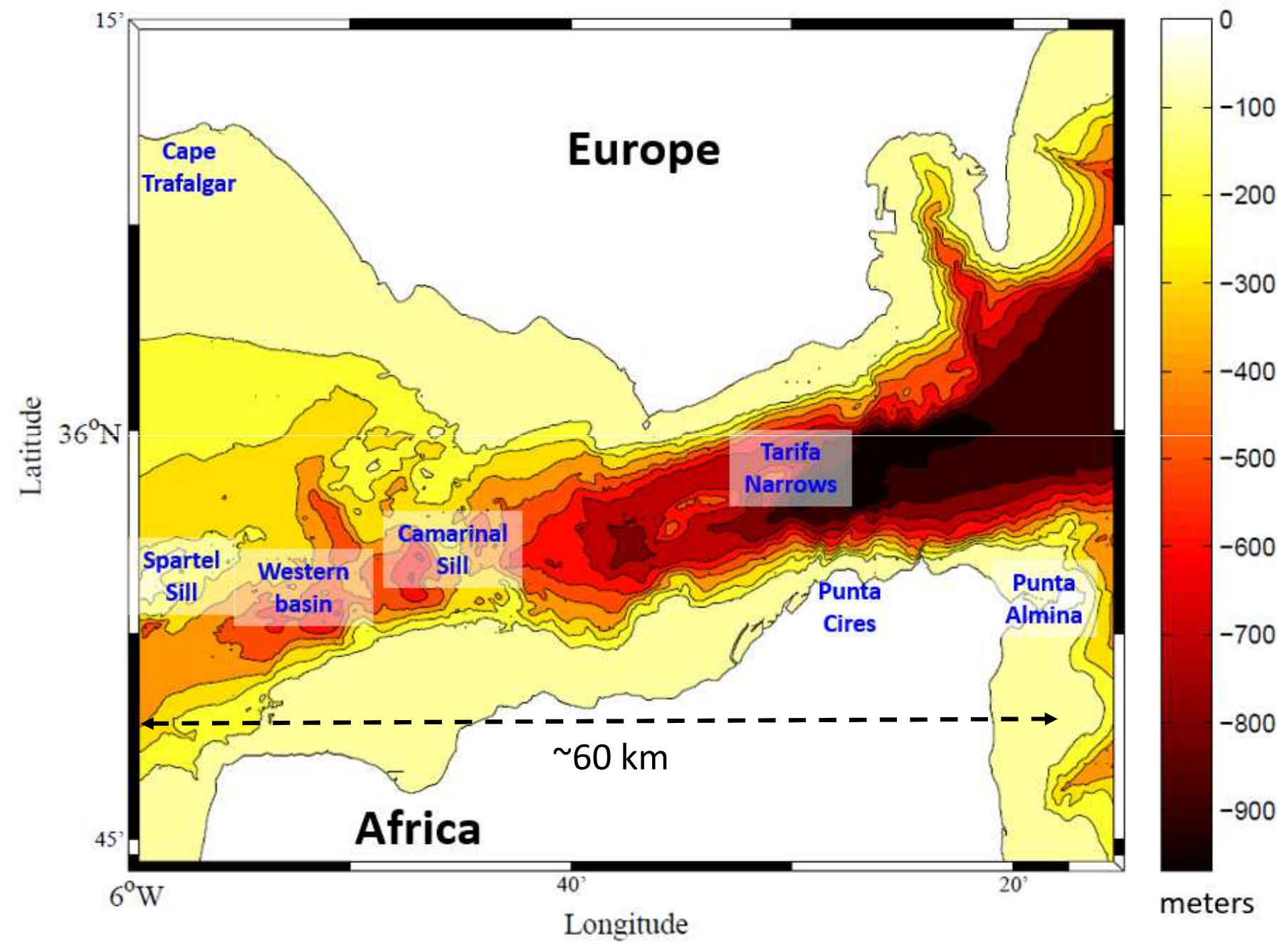

International Review Workshop on Satellite Altimetry CAL/VAL Activities and Applications (Chania - Crete - Greece, 23-26 April 2018) 

along-track high spatial resolution altimeter products

The Strait of Gibraltar: where two worlds meet...

Conclusions

Results

Data sets and

Methods

Study Area

Objective

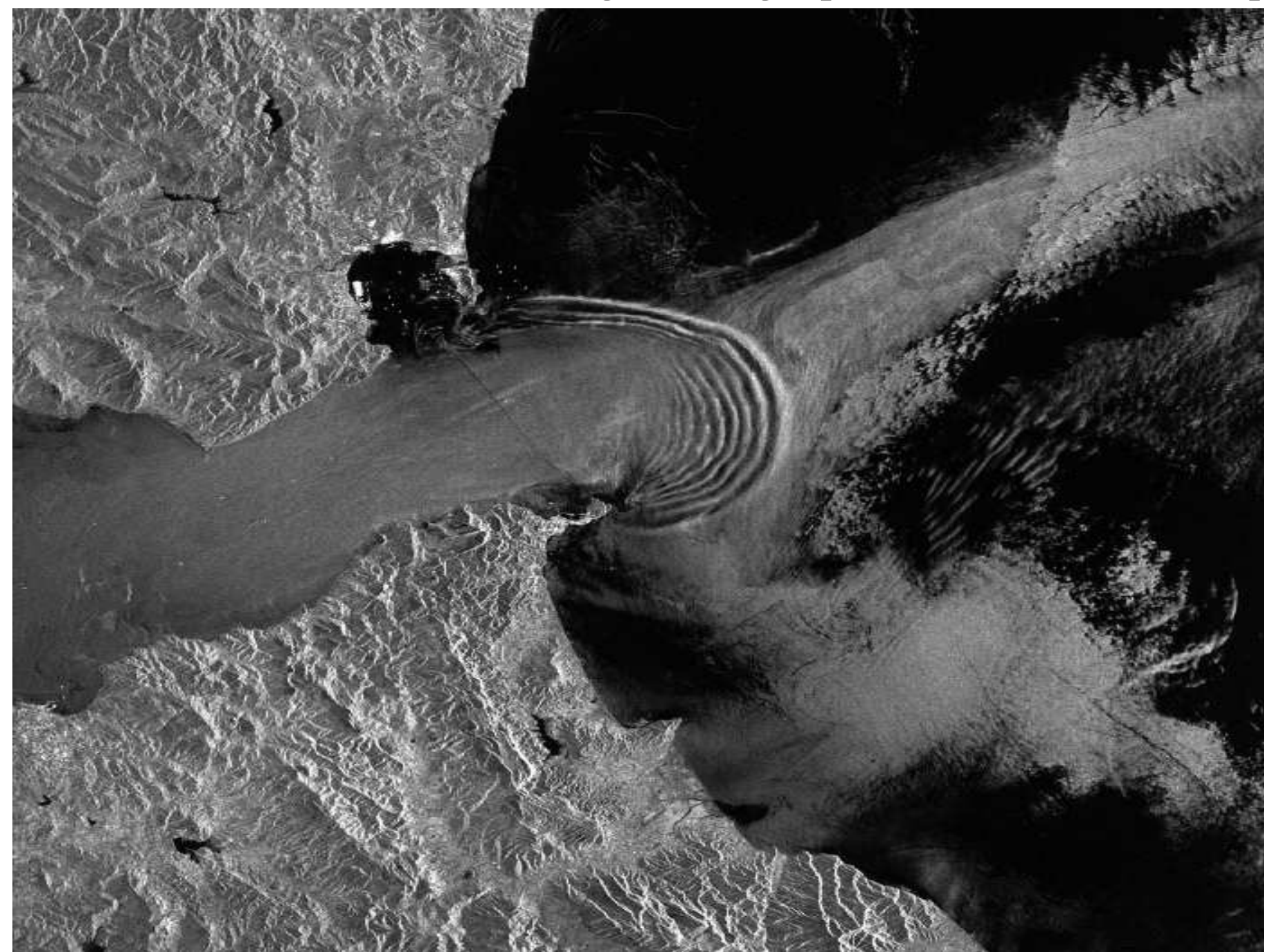

International Review Workshop on Satellite Altimetry CAL/VAL Activities and Applications (Chania - Crete - Greece, 23-26 April 2018) 
Sea level variability in the Strait of Gibraltar from along-track high spatial resolution altimeter products

ESA Envisat RA-2 (SGDR: Phase E2) descending track \#0360: May 2002 (cycle 6) to September 2010 (cycle 93)

\section{Global Tidal Model DTU10}

Local Tidal Model UCA2.5D

Global Mean Sea Surface DTU15MSS

Along-track Local Mean Sea Surface AT_Local_MSS

Acknowledgments

Conclusions

Results

Data sets and Methods

\section{Local MDT UCA2.5D}

Tide gauge and bottom pressure data Study Area Bathymetry and Wind velocity
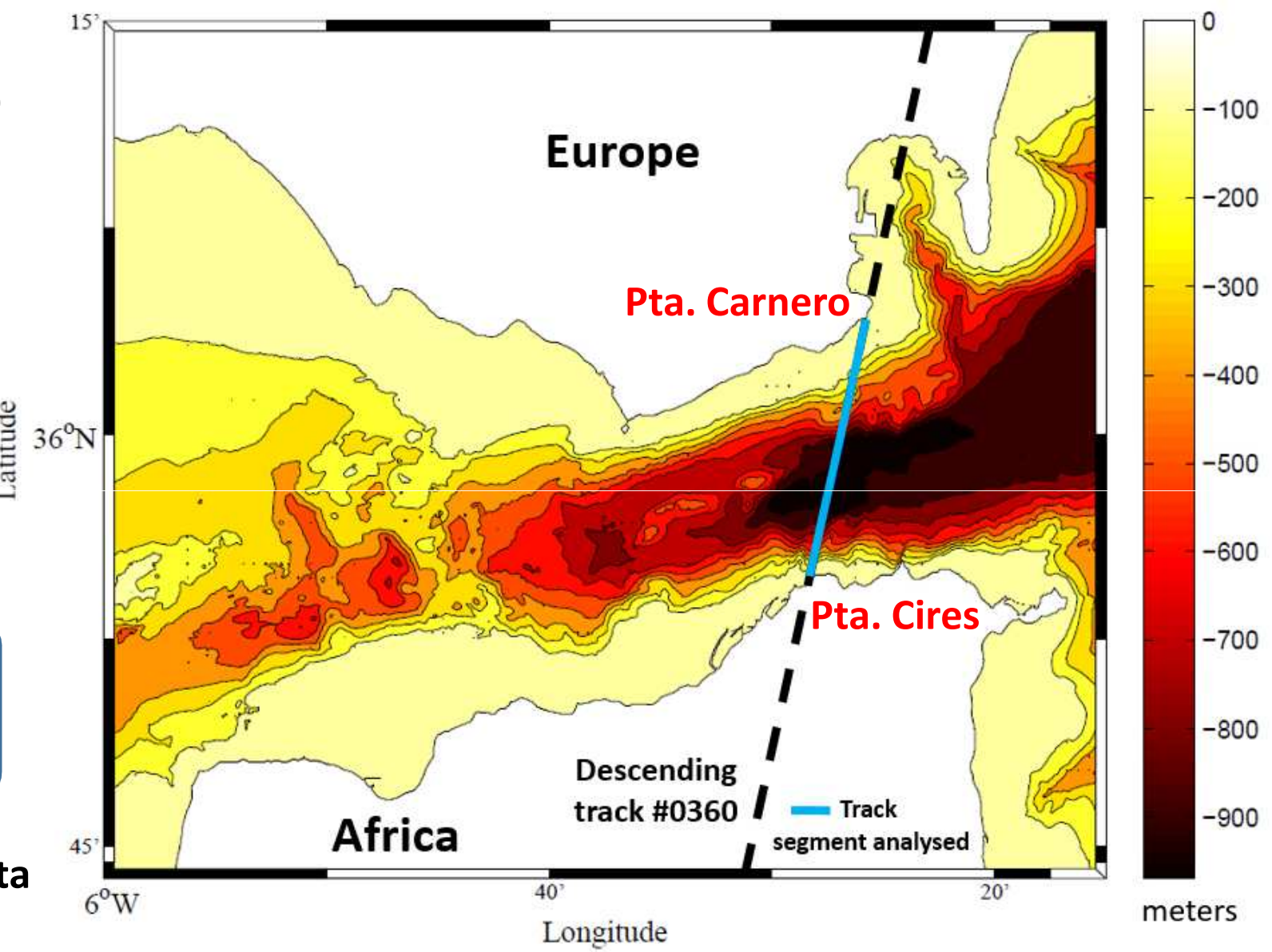

Objective

International Review Workshop on Satellite Altimetry CAL/VAL Activities and Applications (Chania - Crete - Greece, 23-26 April 2018) 

along-track high spatial resolution altimeter products

ESA Envisat RA-2 descending track \#0360 (SGDR $18 \mathrm{~Hz}$ along-track data)

$$
A T \_S L A=\text { Orbit }- \text { Range }- \text { Range Corrections }- \text { Geophysical Corrections }- \text { MSS }
$$

Sensor Geophysical Data Records (SGDR) official product: waveforms, orbit, ionospheric, dry / wet tropospheric, solid earth tide and pole tide corrections (ESA, 2007).

Adaptive Leading Edge Subwaveform (ALES) retracker: Range, Sigma0 and Significant Wave Height (SWH) (Passaro et al., 2014) => recomputed SSB correction (Gómez-Enri et al., 2016)

Acknowledgments

Conclusions

Results

Data sets and

Methods

Study Area

Objective
Danmarks Tekniske Universitet (DTU): mean sea surface (DTU15MSS, Andersen et al., 2016) and tidal model (DTU10, Cheng and Andersen, 2011).

Along track local mean sea surface.

Local Tidal model (UCA2.5D) (Izquierdo et al., 2001). 

along-track high spatial resolution altimeter products

ESA Envisat RA-2 descending track \#0360 (SGDR $18 \mathrm{~Hz}$ along-track data)

$$
A T \_A D T=A T \_S L A+A T \_M D T
$$

Danmarks Tekniske Universitet (DTU): mean dynamic topography (DTU15MDT, Knudsen et al., 2016).

Local mean dynamic topography (UCA2.5D) (Izquierdo et al., 2001).

Acknowledgments

\section{Conclusions}

Results

Data sets and

Methods

Study Area

Objective

International Review Workshop on Satellite Altimetry CAL/VAL Activities and Applications (Chania - Crete - Greece, 23-26 April 2018) 
Sea level variability in the Strait of Gibraltar from along-track high spatial resolution altimeter products

\section{Assessment of models used for corrections}

\section{DTU10 vs. UCA2.5D tidal models}

\section{Acknowledgments}

Conclusions

Results

Data sets and

methods

Study Area

Objective
$R M S$ of the differences and the RSS of the main constituents: $M_{2}$ and $S_{2}$ (semidiurnals), $K_{1}$ and $\mathrm{O}_{1}$ (diurnals) using information from a few tide gauges and bottom pressure instruments located within the Strait of Gibraltar

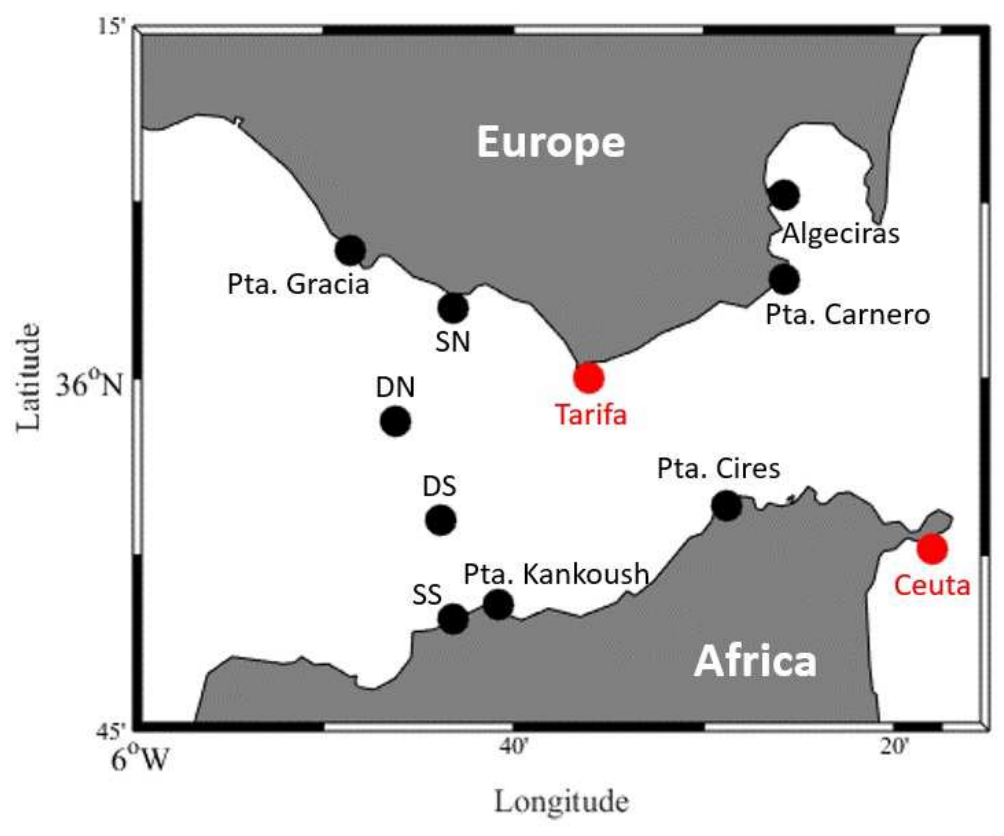

International Review Workshop on Satellite Altimetry CAL/VAL Activities and Applications (Chania - Crete - Greece, 23-26 April 2018) 
Sea level variability in the Strait of Gibraltar from along-track high spatial resolution altimeter products

\section{Assessment of models used for corrections}

\section{Acknowledgments \\ Conclusions}

Results

Data sets and methods Study Area

Objective

\begin{tabular}{|c|c|c|c|c|c|}
\hline & \multicolumn{4}{|c|}{ RMS differences (cm) } & \multirow[b]{3}{*}{ DTU10 / UCA2.5D } \\
\hline & $\mathrm{M}_{2}$ & $\mathrm{~S}_{2}$ & $\mathrm{~K}_{1}$ & $\mathrm{O}_{1}$ & \\
\hline & \multicolumn{4}{|c|}{ DTU10 / UCA2.5D } & \\
\hline Tarifa & $4.9 / 5.6$ & $1.9 / 2.0$ & $0.6 / 1.2$ & $1.3 / 1.7$ & $5.5 / 6.3$ \\
\hline SN & $4.9 / 5.6$ & $2.1 / 1.9$ & $0.4 / 1.0$ & $0.6 / 1.1$ & $5.4 / 6.1$ \\
\hline DN & $0.8 / 4.8$ & $1.0 / 2.4$ & $0.3 / 0.9$ & $1.0 / 0.7$ & $1.7 / 5.5$ \\
\hline DS & $4.0 / 2.4$ & $0.2 / 0.9$ & $0.9 / 1.0$ & $0.9 / 1.2$ & $4.2 / 3.0$ \\
\hline SS & $5.5 / 1.3$ & $2.0 / 0.3$ & $1.7 / 1.0$ & $1.6 / 0.8$ & $6.3 / 1.9$ \\
\hline Pta. Gracia & $3.6 / 6.3$ & $2.2 / 2.2$ & $1.1 / 1.5$ & $0.7 / 1.5$ & $4.4 / 7.0$ \\
\hline $\begin{array}{c}\text { Pta. } \\
\text { Kankoush }\end{array}$ & $7.0 / 3.4$ & $1.5 / 1.3$ & $0.8 / 1.7$ & $1.2 / 1.8$ & $7.3 / 4.5$ \\
\hline $\begin{array}{c}\text { Pta. } \\
\text { Carnero }\end{array}$ & $1.0 / 2.4$ & $0.9 / 0.03$ & $0.5 / 0.5$ & $1.3 / 0.7$ & $2.0 / 2.6$ \\
\hline $\begin{array}{l}\text { Pta. } \\
\text { Cires }\end{array}$ & $4.6 / 4.6$ & $1.2 / 1.3$ & $0.5 / 0.8$ & $1.1 / 0.6$ & $4.9 / 4.9$ \\
\hline Algeciras & $0.6 / 2.8$ & $0.4 / 0.2$ & $0.7 / 0.3$ & $0.6 / 0.7$ & $1.2 / 2.9$ \\
\hline Ceuta & $3.6 / 0.8$ & $1.8 / 0.4$ & $0.1 / 0.4$ & $0.2 / 0.3$ & $4.0 / 1.0$ \\
\hline
\end{tabular}

International Review Workshop on Satellite Altimetry CAL/VAL Activities and Applications (Chania - Crete - Greece, 23-26 April 2018) 
Sea level variability in the Strait of Gibraltar from along-track high spatial resolution altimeter products
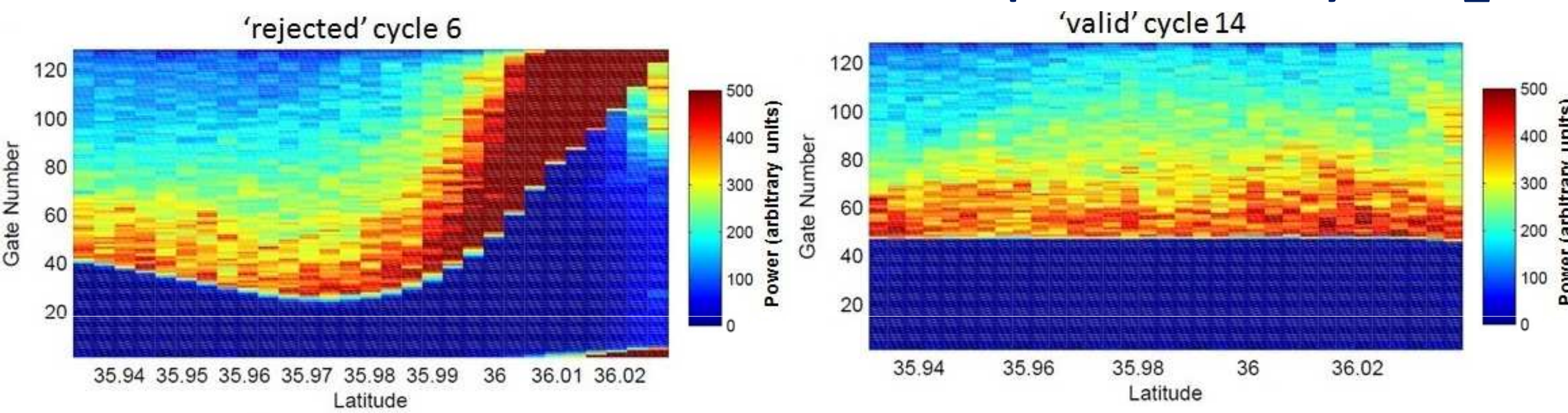

Acknowledgments

Conclusions

Results

Data sets and methods

Study Area

Objective
Initial number of cycles: 78 (it should be 88 !) 'Rejected' cycles: 48 (mainly due to 'non- stable' leading edge) Final number of 'valid' cycles: 30 ('stable' leading edge)

$$
A T \_S L A=\text { Orbit }- \text { Range }- \text { Range Corrections }- \text { Geophysical Corrections }- \text { DTU15MSS }
$$

International Review Workshop on Satellite Altimetry CAL/VAL Activities and Applications (Chania - Crete - Greece, 23-26 April 2018) 
Sea level variability in the Strait of Gibraltar from along-track high spatial resolution altimeter products

Spatial variability of AT_SLA

AT_SLA $=$ Orbit - Range - Range Corrections - Geophysical Corrections - DTU15MSS

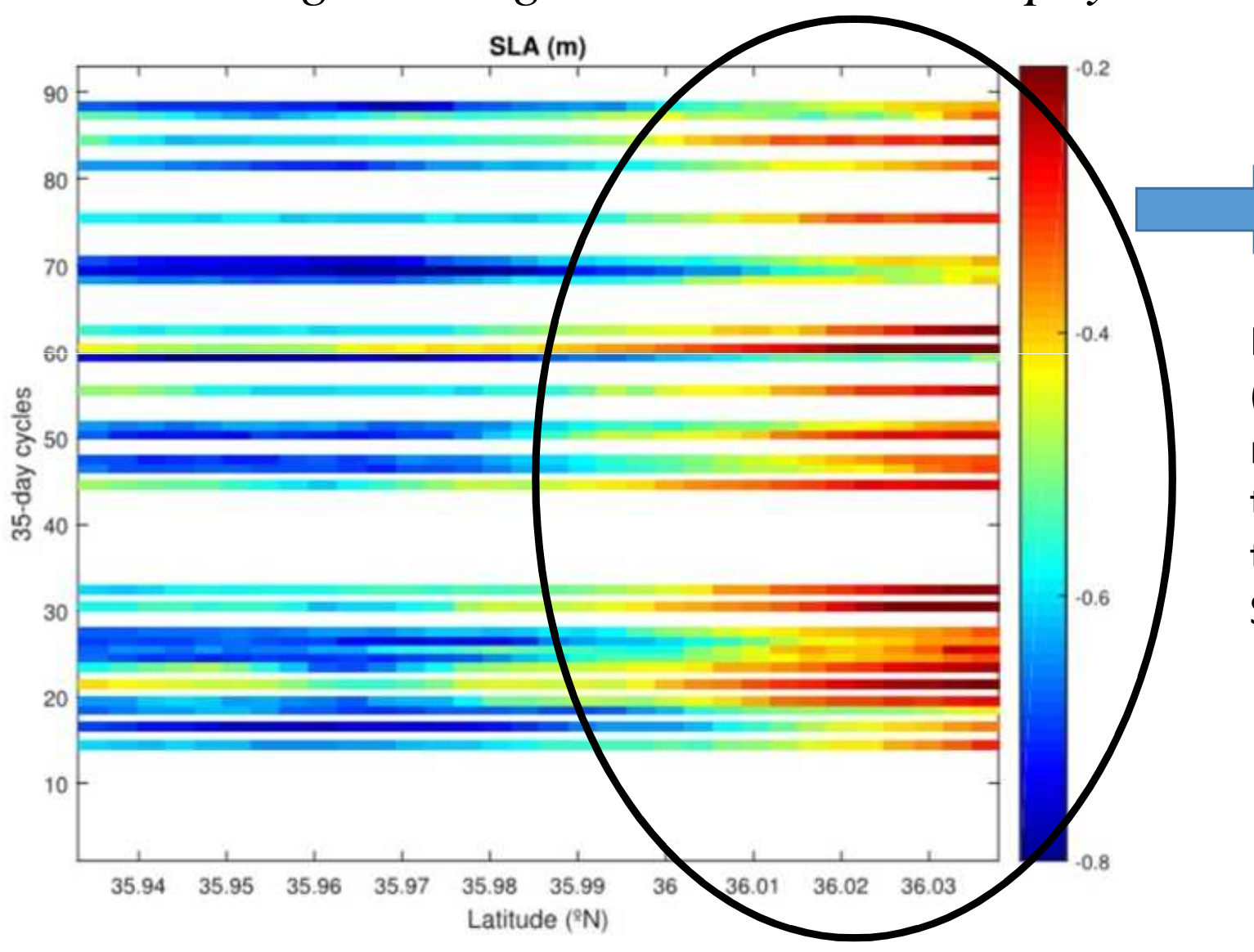

Acknowledgments

Conclusions

Results

Data sets and methods

Study Area

Objective
But, Houston we have a problem...

Bormans and Garret (1989), Ross et al. (2000) and Stanichny et al. (2005) reported that in normal conditions there is a higher / lower sea level on the southern / northern side of the Strait, respectively. 
Sea level variability in the Strait of Gibraltar from along-track high spatial resolution altimeter products

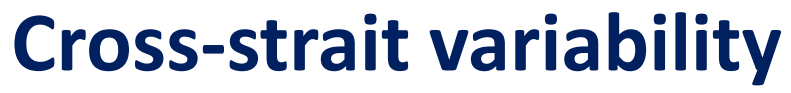

$$
A T \_A D T=A T \_S L A+A T \_M D T
$$

Acknowledgments

Conclusions

Results

Data sets and methods

Study Area
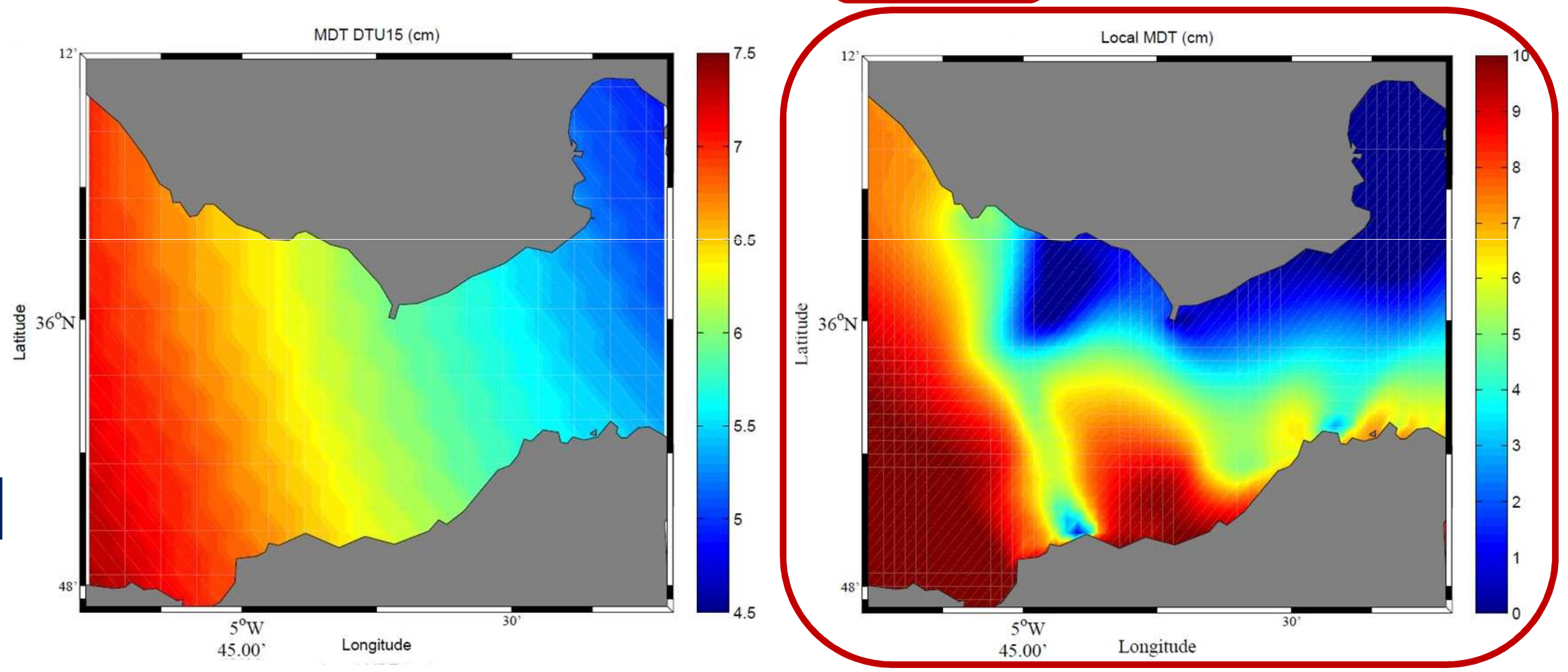

Objective

International Review Workshop on Satellite Altimetry CAL/VAL Activities and Applications (Chania - Crete - Greece, 23-26 April 2018) 

along-track high spatial resolution altimeter products

\section{Cross-strait variability}

(along-track ADT)

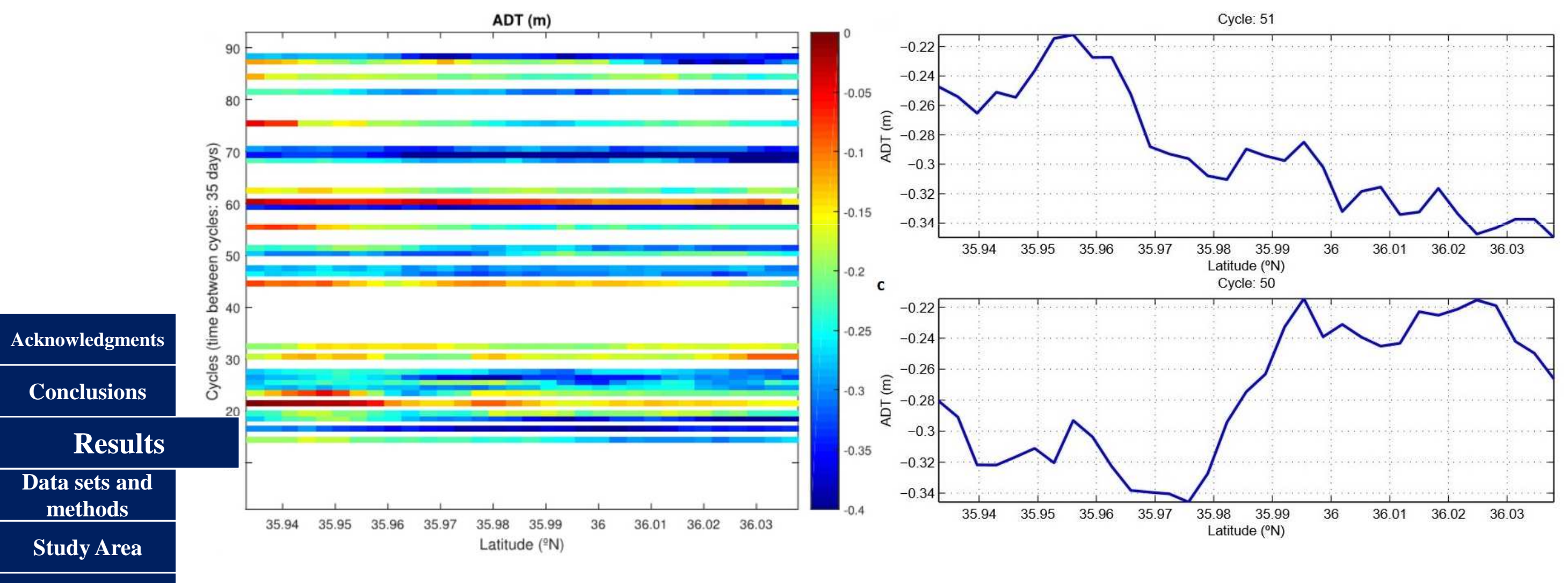

Objective

International Review Workshop on Satellite Altimetry CAL/VAL Activities and Applications (Chania - Crete - Greece, 23-26 April 2018) 
Sea level variability in the Strait of Gibraltar from along-track high spatial resolution altimeter products

\section{Cross-strait variability}

(inversion of the cross-strait sea level drop due to wind regime)

Variability of the cross-strait sea level in the Strait of Gibraltar (eastern side) and its dependence with the wind regime.

Wind information: hourly mean zonal component (û) from a station located in Tarifa.

Comparison made with the sea level difference obtained from two tide gauges located in Ceuta (southern coast of the Strait) and Tarifa (northern coast).

Acknowledgments

Conclusions

Results

Data sets and

methods

Study Area

Objective
South

'Poniente' wind

(West)

Positive û

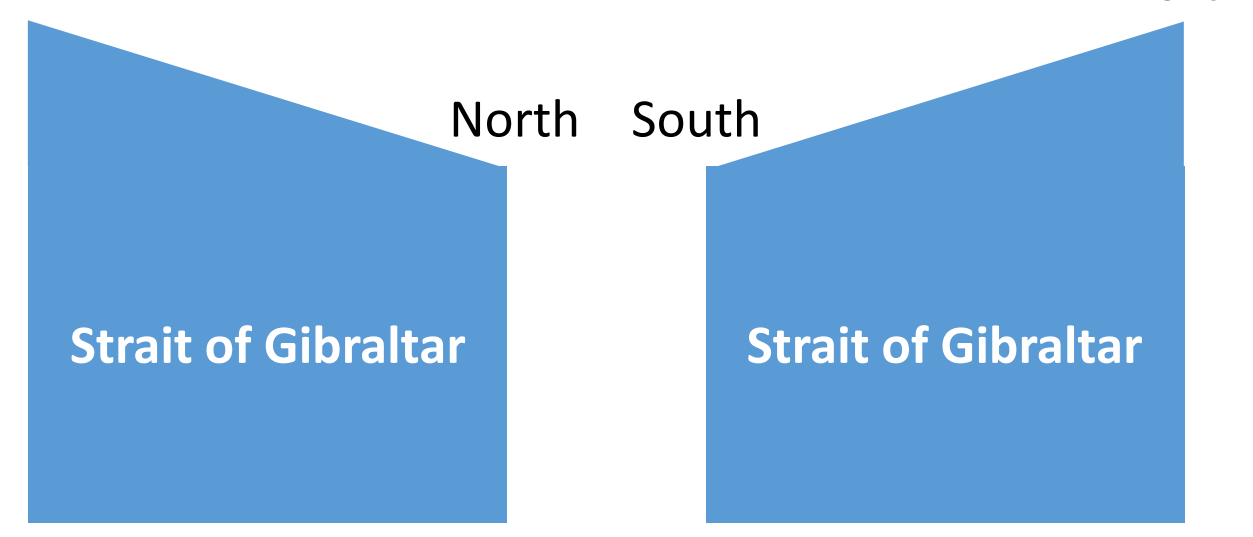

'Levante' wind

(East)

Negative û

International Review Workshop on Satellite Altimetry CAL/VAL Activities and Applications (Chania - Crete - Greece, 23-26 April 2018) 
The global tidal model DTU10 shows a good performance in the Strait of Gibraltar to de-tide altimetric records.

The use of a global MSS in the Strait of Gibraltar to obtain the anomalies might hide some of the sea level variability, and hence complicate their oceanographic interpretation.

An ad-hoc local along-track MSS (based on ERS2/Envisat) gives a more realistic cross-strait variability in the Strait. This improves the analysis of the oceanographic processes in the area.

Conclusions

Results

Data sets and methods

Study Area

Objective
The analysis of the along-track ADT showed a positive correlation with the zonal component of the wind. 

along-track high spatial resolution altimeter products

\section{Acknowledgments}

Conclusions

Results

Data sets and methods

Study Area

Objective

International Review Workshop on Satellite Altimetry CAL/VAL Activities and Applications (Chania - Crete - Greece, 23-26 April 2018) 


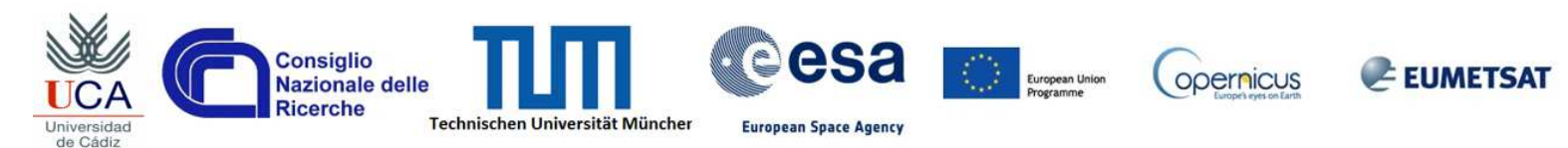

Sea level variability in the Strait of Gibraltar from along-track high spatial resolution altimeter products

\section{FUTURE WORK...}

SENTINEL-3B

SENTINEL-3A

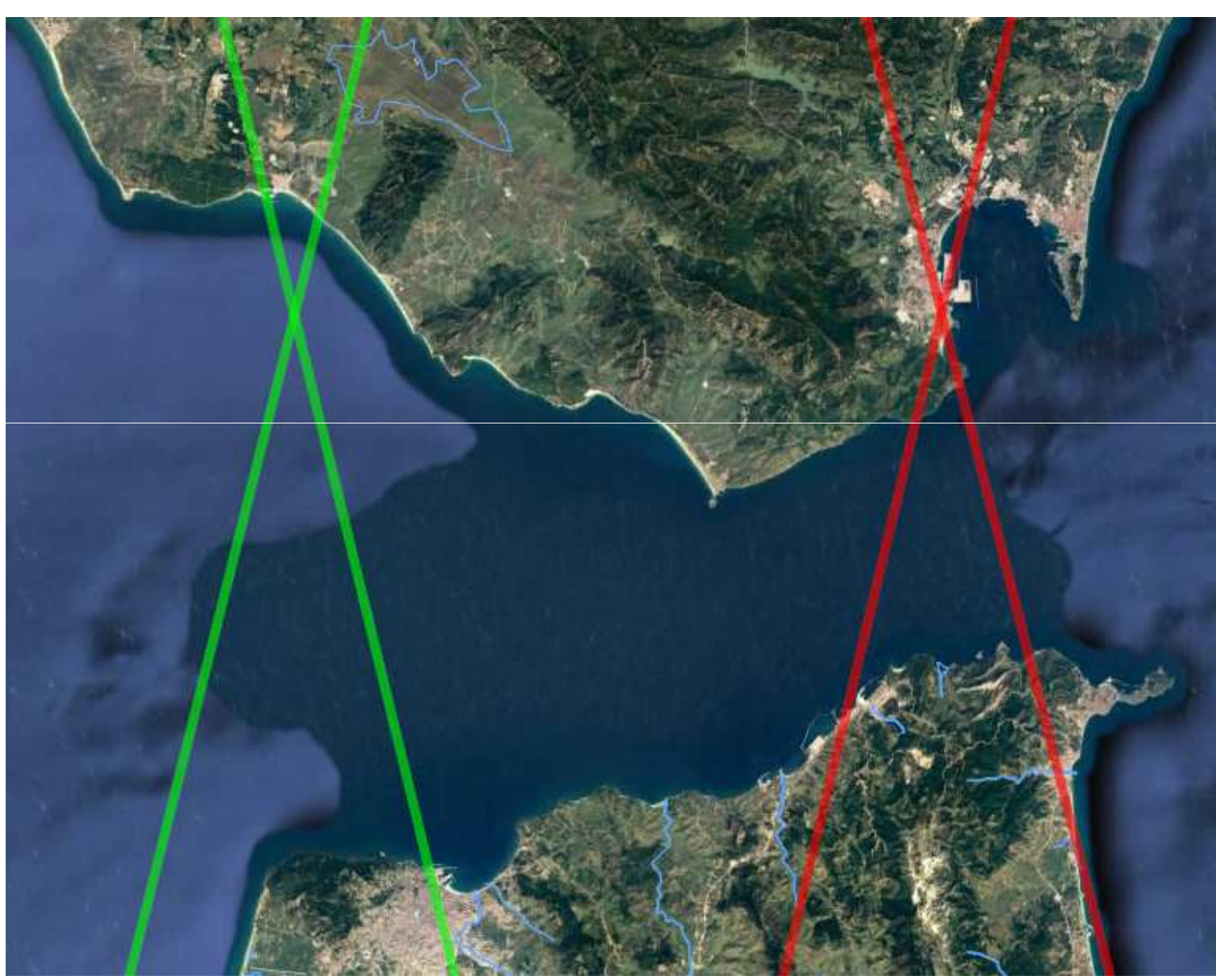




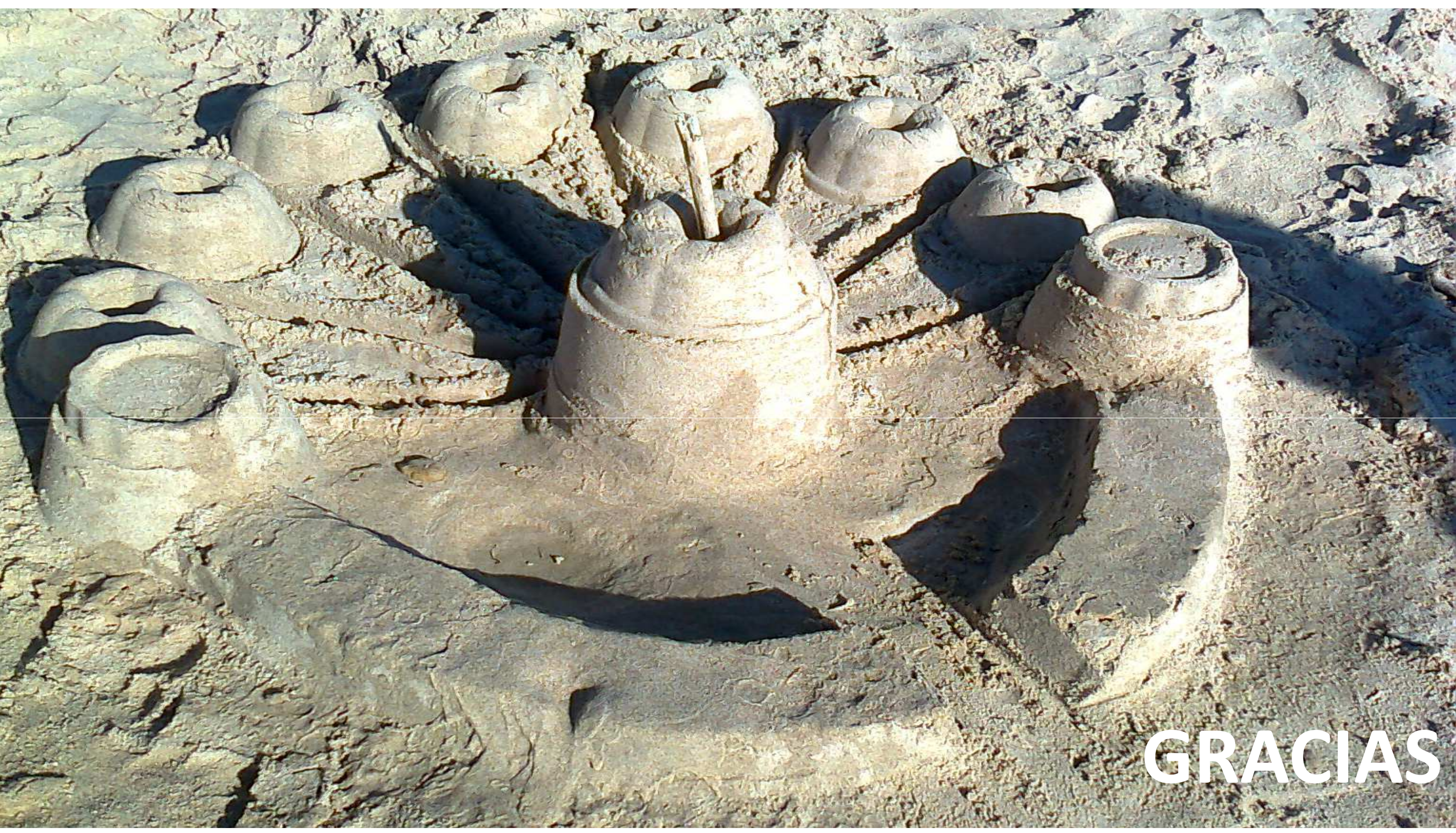

